\title{
Factors Affecting the Success of Step-up Therapy in Patients With Moderate-Severe Asthma: A Real-Life Study
}

\author{
Delgado J', Martinez-Moragón E², Fernández-Sánchez T³ \\ 'Allergology Clinical Management Unit, Hospital Virgen Macarena, Sevilla, Spain \\ ${ }^{2}$ Respiratory Medicine Department, Hospital Universitario Dr. Peset, Valencia, Spain \\ ${ }^{3}$ Medical Department, Mundipharma Pharmaceuticals, Madrid, Spain
}

J Investig Allergol Clin Immunol 2021; Vol. 31(2): 145-150

doi: 10.18176/jiaci.0470

\begin{abstract}
Background: Clinical practice guidelines recommend regular adjustment of treatment to achieve control of asthma. A step-up approach based on the degree of disease control should be followed.

Objective: To perform a real-life analysis of the factors that affect the success or failure of this therapeutic strategy and of the criteria applied by clinicians when applying a step-up approach in a representative sample of patients diagnosed with moderate-severe asthma. Material and Methods:We performed a multicenter retrospective cohort study involving 226 Spanish specialist physicians (98 allergologists, 127 pulmonologists, and 1 family physician). We included 1254 patients (787 women) diagnosed with moderate-severe asthma who underwent step-up therapy during 2016.

Results: Step-up was successful in $44 \%$ of cases. The factors associated with success were presence of $<2$ comorbid conditions, lower grade of severity and therapy step before modification, absence of exacerbations during the previous year, fewer daytime/nighttime symptoms, and limitation in activities, as well as type of inhaled corticosteroid/ long-acting $\beta_{2}$-agonist combination after modification, lower body mass index, and higher fractional exhaled nitric oxide. An early increase in the maintenance dose once a lack of control was detected ( $\leq 3$ months, $>3$ to $\leq 6$ months, $>6$ to $\leq 12$ months) was more likely to be successful.

Conclusion: The factors that determine whether or not this therapeutic strategy manages to control asthma are time since onset of clinical impairment, previous grade of severity, number of comorbid conditions, previous exacerbations, and frequency of symptoms.
\end{abstract}

Key words: Asthma. Treatment. Step up. Real-life.

\section{Resumen}

Antecedentes: Las guías de práctica clínica recomiendan el ajuste del tratamiento hasta alcanzar el control del asma, siguiendo un escalado progresivo basado en el grado de control de la enfermedad.

Objetivo: Realizar un análisis en vida real de los criterios que utilizan los clínicos para realizar el escalado terapéutico y de los factores que condicionan el éxito o el fracaso de esta estrategia terapéutica en una muestra representativa de pacientes diagnosticados de asma persistente moderada y grave.

Material y métodos: Estudio multicéntrico retrospectivo de cohorte en el que participaron 226 médicos especialistas españoles (98 alergólogos, 127 neumólogos y un médico de atención primaria). Incluimos 1.254 pacientes (787 mujeres) diagnosticados de asma persistente moderada o grave en los que se realizó un escalado de tratamiento durante 2016.

Resultados: El escalado terapéutico fue exitoso en el $44 \%$ de los casos. Los factores asociados con el éxito fueron la presencia de $<2$ comorbilidades, menor grado de gravedad y del escalón terapéutico de la terapia antes de la modificación, ausencia de exacerbaciones durante el año anterior, menos síntomas diurnos/nocturnos y limitación en las actividades ordinarias, así como el tipo de corticosteroide inhalado (ICS) / combinación de $\beta_{2}$-agonista de acción prolongada (LABA) después de la modificación, índice de masa corporal inferior y fracción del óxido nítrico exhalado superior. Un aumento temprano en la dosis de mantenimiento una vez que se detectó una falta de control ( $\leq 3$ meses, $>3$ a $\leq 6$ meses, $>6$ a $\leq 12$ meses) también se asoció a un aumento de probabilidad de éxito.

Conclusión: Los factores que determinan si el escalado terapéutico logra controlar el asma son el tiempo transcurrido desde el inicio del deterioro clínico, el grado previo de gravedad, el número de afecciones comórbidas, las exacerbaciones previas y la frecuencia de síntomas.

Palabras clave: Asma. Tratamiento. Escalado. Vida real. 


\section{Introduction}

The main objectives of asthma treatment are to achieve and maintain disease control, prevent exacerbations, prevent chronic airway obstruction, and reduce mortality to the lowest levels possible [1,2].

In order to achieve control of asthma, clinical practice guidelines recommend regular adjustment of treatment comprising a step-up approach based on the degree of disease control after rechecking on diagnosis, adherence, and technique [1,2]. If asthma is not well controlled, treatment should be stepped up until control is achieved, with continuous evaluation of nonpharmacological measures, adherence, and modifiable aggravating and risk factors. Despite these recommendations, step-up is carried out in real-life practice without the necessary control of technique/adherence very often. The first recommendation for therapy is a short-acting $\beta_{2}$-agonist (as needed) in intermittent asthma, with the addition of a low-dose inhaled corticosteroid (ICS) in persistent asthma and increased dose of ICS combined with a long-acting $\beta_{2}$-agonist (LABA) in moderate and severe asthma. Controller medication (antileukotriene drugs, long-acting muscarinic antagonists, or biologics) can be added until the disease is controlled. The GINA 2019 guidelines now recommend that all adults and adolescents with asthma receive symptomcontrolled (mild asthma) or regular treatment that contains ICS to reduce the risk of serious exacerbations [1].

However, in daily clinical practice, disease remains uncontrolled in more than half of patients managed using this strategy [3]. Many factors are involved in the failure of antiasthma treatment in a specific patient, despite the availability of potent and effective therapeutic tools. One factor that could contribute to failure is the absence of clearly specified, relevant clinical data in consensus guidelines to help clinicians with their decision to increase the dose of medication.

Several recommendations have been made to ensure that step-up therapy is effective [4-6], yet very few studies have examined the real-life criteria applied by physicians when deciding on a progressive dose increase in patients with uncontrolled asthma. Similarly, few data are available on the clinical factors that can affect the success of this approach.
When and how to implement a sustained increase in the dose of maintenance medication and the aspects affecting its success or failure remain to be elucidated.

We designed a study to analyze the real-life factors that affect the success or failure of step-up therapy and the criteria applied by clinicians when adopting this approach in a representative sample of patients diagnosed with moderatesevere asthma.

\section{Material and Methods}

We performed a multicenter, retrospective, cohort study based on data from 226 participating researchers in Spain. The researchers were all specialist physicians (98 allergologists, 127 pulmonologists, and 1 family physician). Each researcher included 5-10 consecutive patients who had attended their clinic during 2017 and had been diagnosed with persistent moderatesevere asthma under treatment with fixed combinations of ICS/ LABA. Therapy had been stepped up at least once during 2016. The face-to-face inclusion interview was held between January and March 2017. We retrospectively analyzed modifications to therapy during the previous year, the factors that led to the decision taken, and outcomes measured according to the degree of control of asthma (Figure 1). The complementary tests were performed according to daily clinical practice. Prior to step-up, relevant factors associated with poor asthma control were evaluated and acted on, namely, therapeutic adherence, comorbidities, exposure to allergens/irritants.

As this study was a retrospective real-life study, asthma was managed following the investigator's criteria, and, as such, reflects clinical practice. However, the investigators were respiratory specialists, and the Spanish Guidelines on Asthma Management (GEMA) [2] are extensively followed. Switching ICS/LABA combinations was allowed. In severe asthma patients, we considered step-up the change from step 5 to 6 of the GEMA guidelines.

The patients included signed the informed consent document before the interview and collection of their data for the study. A clinical history focusing on asthma was taken for all patients. This covered time since diagnosis, severity, control, associated comorbidities, and treatment administered.

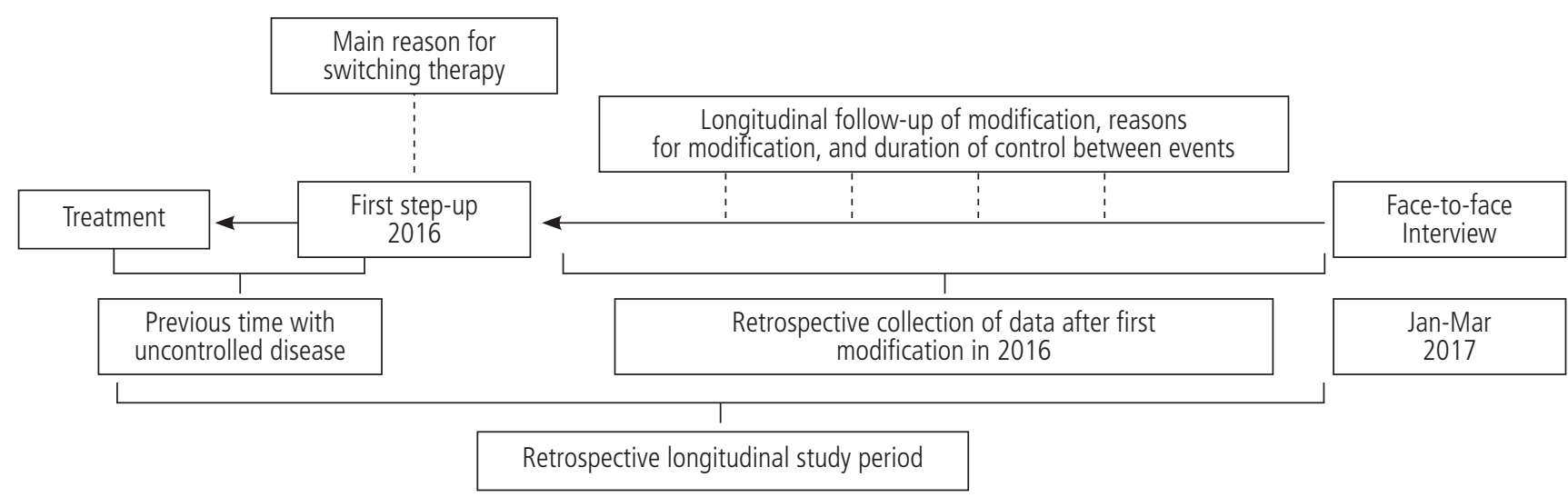

Figure 1. Study design. 


\section{Statistical analysis}

Quantitative variables were expressed as measures of central tendency and dispersion (mean, standard deviation [SD], minimum, and maximum). Qualitative variables were reported as absolute and relative frequencies.

When inferential analysis proved necessary, parametric tests were used to evaluate continuous variables and nonparametric tests to evaluate ordinal, categorical, and nonparametric variables. All hypothesis tests were 2-sided, with significance set at 0.05 . Nonnormally distributed variables were assessed using the Mann-Whitney test (unpaired data) or Wilcoxon test (paired data). The $\chi^{2}$ test (or Fisher exact test where applicable) was used for the contingency table analysis and for the comparison of proportions and/or frequency distributions.

Logistic regression analysis was performed to determine predictors of success or failure of intensifying treatment based on patient outcome. Some variables were categorized for the statistical analysis, as follows: body mass index $(<25,25-30$, and $>30$ ), number of comorbid conditions ( $<2$ or $\geq 2)$, time since diagnosis ( $\leq$ or $>10$ years), duration of clinical impairment before therapy was modified ( $\leq 3$ months, $>3$ to $\geq 6$ months, $>6$ months), presence/absence of daytime symptoms ( $\leq 2$ or $>2$ times per week), forced expiratory volume in the first second $\left(\mathrm{FEV}_{1}, \%\right)$ in baseline spirometry $(<60,60-80,>80)$, and eosinophil count $\left(<300\right.$ or $\left.\geq 300 / \mathrm{mm}^{3}\right)$.

The data were analyzed using PASW Statistics for Windows, Version 18.0 (SPSS Inc) or a subsequent version.

Step-up was considered successful if the patient fulfilled all of the following conditions at the face-to-face (inclusion) visit: no need for an additional dose increase after the first change, no asthma exacerbations, no treatment-induced adverse effects, and controlled disease, defined as an Asthma Control Test (ACT) score $\geq 20$. Step-up therapy was considered to have failed if the patient did not fulfill all of the conditions for therapy to be considered successful. Exacerbations were identified retrospectively from systemic corticosteroid use or an increase from a stable maintenance dose, for at least 3 days and/or hospitalizations or unscheduled visits to the doctor requiring systemic corticosteroids [7].

\section{Results}

The study population included 1254 patients, of whom 787 (63\%) were women. The mean (SD) age was $49.6(16.6)$ years, with a mean (SD) age at diagnosis of asthma of 37 (18.6) years. Most patients were nonsmokers (89\%). As for type of asthma, $62 \%$ had allergic asthma, $75 \%$ had moderate-persistent asthma, and $25 \%$ had severe-persistent asthma. At the inclusion visit, disease was controlled (ACT $\geq 20$ ) in $57 \%$ of patients (in $61 \%$ of those with moderate disease, and in $44 \%$ of those with severe disease). Disease was uncontrolled (ACT <20) in $43 \%$ of patients (in $39 \%$ of those with moderate disease, and in $56 \%$ of those with severe disease). The mean (SD) time patients were followed was 7.5 (3.8) months. Step-up was successful in $44 \%$ of cases.

The allergologist/pulmonologist's reasons for stepping up therapy were essentially clinical: daytime symptoms more than twice per week ( $35 \%$ of cases), limitations in activities (19\%), exacerbations $(12 \%)$, and nighttime symptoms/awakening (10.5\%). More complex parameters such as the ACT were evaluated in all patients but only used in $4.6 \%$ of cases for step-up. Lung function was evaluated in 2165 patients (99.9\%), and changes in lung function led to step-up in only $9 \%$ of cases. Fractional exhaled nitric oxide (FeNO) levels were evaluated in 549 patients $(25.3 \%)$ and were the main reason for changing therapy in $0.5 \%$ of cases (Table 1 ).

The most frequent change was to increase the dose of ICS in the ICS+LABA combination, until a high dose was reached. In patients in whom a new drug was added to maintenance treatment, a long-acting muscarinic antagonist was the most frequently added drug (Table 2).

Table 1. Main Clinical Reasons for Performing Step-upa

\begin{tabular}{lcc}
\hline Reason & No. & $\%$ \\
\hline Daytime symptoms $>$ 2/wk & 437 & 34.9 \\
Limitations in daily activities & 243 & 19.4 \\
Exacerbations & 146 & 11.7 \\
Nighttime symptoms/awakenings & 131 & 10.5 \\
Pulmonary function & 111 & 8.9 \\
Rescue therapy needed $>2$ times/wk & 92 & 7.3 \\
Asthma control test & 57 & 4.6 \\
Other & 15 & 1.2 \\
Bronchodilator reversibility testing & 14 & 1.1 \\
FeNO & 6 & 0.5 \\
Total & 1,252 & 100 \\
\hline
\end{tabular}

Abbreviation: FeNO, fractional exhaled nitric oxide. ${ }^{\text {DD }}$ ata were unavailable for 2 patients.

Table 2. Summary of the Main Treatment Changes After Step-up

\begin{tabular}{|c|c|c|c|c|}
\hline & \multicolumn{2}{|c|}{$\begin{array}{l}\text { Prechange } \\
\text { Treatment }\end{array}$} & \multicolumn{2}{|c|}{$\begin{array}{l}\text { Postchange } \\
\text { Treatment }\end{array}$} \\
\hline & No. & $\%^{\mathrm{a}}$ & No. & $\%{ }^{\mathrm{a}}$ \\
\hline High-dose ICS+LABA & 318 & 25.4 & 732 & 58.4 \\
\hline SABA & 734 & 58.5 & 572 & 45.6 \\
\hline LTRA & 125 & 10.0 & 192 & 15.3 \\
\hline LAMA & 115 & 9.2 & 259 & 20.7 \\
\hline SAMA & 39 & 3.1 & 36 & 2.9 \\
\hline OCS & 18 & 1.4 & 34 & 2.7 \\
\hline Biological drugs & 15 & 1.2 & 36 & 2.9 \\
\hline LAMA/LABA & 1 & .1 & 2 & .2 \\
\hline Theophylline & 1 & .1 & 1 & .1 \\
\hline
\end{tabular}

Abbreviations: ICS, inhaled corticosteroids; LABA, long-acting $B_{2-}$ agonist; LAMA, long-acting muscarinic antagonist; LTRA, leukotriene receptor antagonist; OCS, oral corticosteroids; SABA, short-acting beta2-agonist; SAMA, short-acting muscarinic antagonist. aPercentages calculated on the total number of patients analyzed $(\mathrm{N}=1254)$. 
Comorbid conditions associated with asthma were recorded in $49 \%$ of patients, and $32 \%$ had at least 2 conditions associated with the disease. The most frequent concomitant diseases were rhinoconjunctivitis $(64.5 \%)$, nasal polyposis $(18 \%)$, gastroesophageal reflux disease (16\%), depression-anxiety (13.6\%), and sleep apnea-hypopnea syndrome (8\%).

The factors associated with the success of step-up therapy were as follows: presence of $<2$ comorbid conditions, lower grade of severity and lower therapeutic step before modification, absence of exacerbations during the previous year, fewer daytime/nighttime symptoms, and limitation of activities, as well as the type of ICS/LABA combination after modification, younger age, lower body mass index, and higher FeNO value. Male sex was also associated with the success of step-up therapy. Similarly, duration of uncontrolled disease proved to be decisive with respect to the success or failure of

Table 3. Factors Associated With Successful Step-up

\begin{tabular}{|c|c|}
\hline Factor & $P$ Value \\
\hline Male sex & $<.001$ \\
\hline Lower age ${ }^{b}$ & .011 \\
\hline Lower BMI $(<25,25-30,>30)$ & .007 \\
\hline$<2$ respiratory comorbidities & $<.001$ \\
\hline Lower severity (moderate, severe) & $<.001$ \\
\hline Less time since diagnosis $(\leq$ or $>10 y)$ & .012 \\
\hline Lower prechange treatment step (step 3 to 6 ) & .001 \\
\hline Lower postchange treatment step (step 3 to 6 ) & $<.001$ \\
\hline $\begin{array}{l}\text { Less time with clinical worsening before the change } \\
(\leq 3 \mathrm{mo},>3 \text { to } \leq 6 \mathrm{mo},>6 \text { to } \leq 12 \mathrm{mo})\end{array}$ & .039 \\
\hline Absence of exacerbations & $<.001$ \\
\hline Absence of daytime symptoms ( $<2$ times/week) & $<.001$ \\
\hline Absence of nighttime symptoms & $<.001$ \\
\hline Absence of limitations in daily activities & .001 \\
\hline Well-controlled asthma according to ACT or ACQ & $<.001$ \\
\hline Higher FeNOb & .006 \\
\hline Postchange ICS/LABA combination & $<.001$ \\
\hline Smoking & 647 \\
\hline Allergic asthma & .069 \\
\hline Age at diagnosis $(\leq$ or $>40$ y) & .387 \\
\hline $\mathrm{FEV}_{1} \%$ predicted $(<60,60-<80, \geq 80)$ & .691 \\
\hline Rescue needed ( $\leq$ or $>2$ times/wk) & .508 \\
\hline Bronchodilator reversibility testing ( + or - result) & .125 \\
\hline Eosinophilia $(\leq$ or $>300$ cells $/ \mu \mathrm{L})$ & .659 \\
\hline
\end{tabular}

Abbreviations: ACQ, Asthma Control Questionnaire; ACT, Asthma Control Test; BMI, body mass index; FeNO, fractional exhaled nitric oxide; FEV 1 , forced expiratory volume in the first second; ICS, inhaled corticosteroids; LABA, long-acting $B_{2}$-agonist.

aThe $P$ value is calculated based on the number of patients with available data for each factor.

${ }^{b}$ Factor studied as a continuous variable.

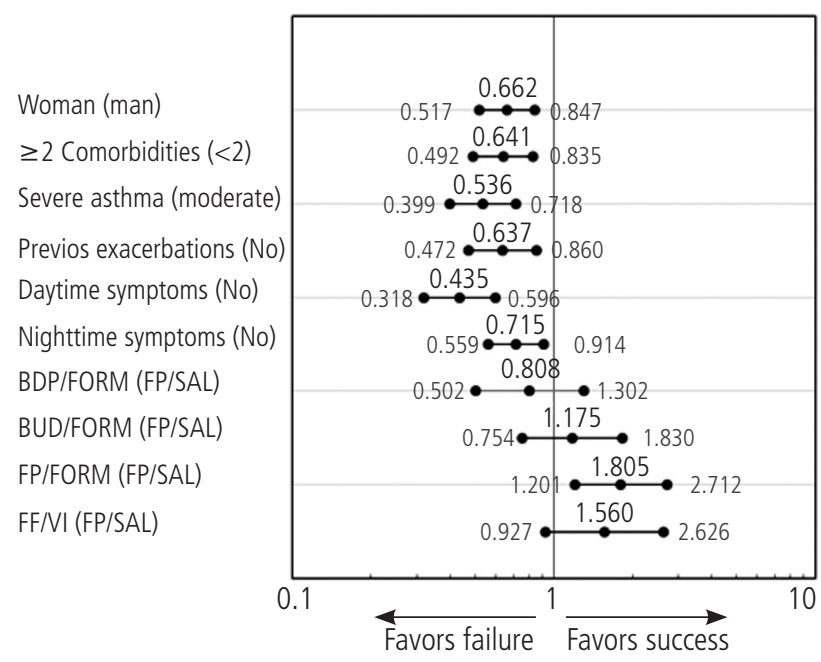

Figure 2. OR $(95 \% \mathrm{Cl})$ of statistically significant factors for step-up. The reference categories are shown in parenthesis ( $N=1240$ patients). The combinations of ICS/LABA are those prescribed after step-up. BDP indicates beclomethasone; FORM, formoterol; $F P$, fluticasone propionate; SAL, salmeterol; BUD, budesonide; FF, fluticasone furoate; VI, vilanterol.

step-up therapy: the sooner therapy was stepped up, the more likely it was to be successful (Table 3).

The factors that were not shown to be associated with the success or failure of step-up were blood eosinophil counts, result of the bronchodilation test, $\mathrm{FEV}_{1}$ values in baseline spirometry, smoking, and type of asthma (allergic or nonallergic) (Table 3 ).

A logistic regression analysis was performed with success/ failure of step-up as the dependent variable and variables with a $P$ value $<.20$ in the bivariate analysis in Table 3 as independent variables.

Figure 2 shows the OR and its corresponding 95\%CI. The factors favoring failure of step-up were female sex, $\geq 2$ comorbid conditions associated with asthma, severe vs moderate asthma, previous exacerbations, and daytime/ nighttime symptoms. Furthermore, the type of ICS/LABA used after the change was a predictive factor, since one of the factors of success was using the combination fluticasone propionate/ formoterol compared with fluticasone propionate/salmeterol. There were no statistically significant differences between the remaining combinations and fluticasone propionate/salmeterol.

When patients were divided into moderate and severe asthma, the multivariate analysis indicated that the factors that significantly favor failure were as follows (OR, 95\% CI): $\geq 2$ comorbidities $(-0.605,0.450-0.813)$, daytime symptoms $(-0.394,0.279-0.557)$ in moderate patients; and daytime symptoms $(-0.476,0.260-0.870)$ and beclomethasone dipropionate/formoterol vs fluticasone propionate/salmeterol $(0.292,0.116-0.735)$ in patients with severe disease.

\section{Discussion}

The recommended therapeutic strategy in asthma consensus guidelines [1,2] is to increase the dose of ICS in patients diagnosed with uncontrolled persistent asthma. This 
recommendation has become standard clinical office practice for patients with uncontrolled disease receiving low-to-medium doses of ICS/LABA (step-up). However, this basic structure is very general in nature and offers a uniform response to all patients with uncontrolled asthma, who generally vary considerably in terms of etiology, outcome, and prognosis. Nevertheless, few studies analyze the conditions that predict its success or failure in a specific patient [8].

Several studies have underestimated the severity of asthma by clinicians, especially in patients with severe persistent asthma; therefore, the use of objective measures for the assessment of these patients should be advised $[9,10]$. However, according to the results, the decision is based on essentially clinical criteria, especially the presence of daytime asthma symptoms, as is the case in similar conditions such as chronic obstructive pulmonary disease [11]. However, although simple parameters could be used to confirm control of asthma [12], there is evidence that the use of more complex parameters such as the ACT score could increase the possibility of dose intensification being successful [10].

One of the factors that facilitates the success of step-up is ensuring that it is performed during the first months of clinical impairment: the chances of success increase, the earlier the intervention is applied. However, the time criterion is not mentioned in consensus guidelines $[1,2]$, even though this may be a fundamental aspect of current treatment and an indicator of future risk in patients with uncontrolled asthma, especially those with moderate and severe disease: longer periods of poor control (and onset of exacerbations) increase the likelihood of a permanent, less reversible structural alteration that reduces the efficacy of intensifying any subsequent maintenance treatment. Furthermore, systemic absorption of high doses of ICS is diminished in patients with intense inflammation of the airway [13], which could affect the response to therapy. Therefore, it is necessary to establish the window of opportunity that optimizes step-up therapy, which, according to the data obtained, should not be more than 3 months in a patient with clinical impairment, especially in cases of moderate and severe asthma.

Male sex was also associated with the success of step-up in our study, although this may be affected by the presence in the sample of a significantly greater percentage of severe asthma in women $(29 \%)$ than in men $(19.5 \%)$, given that lower severity of asthma increased the likelihood of successful step-up therapy.

High FeNO levels also favor the success of step-up therapy, probably because of the efficacy of increasing the ICS dose in asthma patients with an allergic or eosinophilic phenotype, in whom levels of this marker are generally elevated.

The type of combination recommended to the patient also enhances the success of step-up therapy: the combination of fluticasone/formoterol proved to be more effective for achieving a positive response to step-up. This finding could be associated with the fact that the marketed combination of fluticasone/formoterol at high doses makes it possible to double the dose both of the ICS and of the LABA, in contrast with other combinations, which only double the dose of the ICS, thus leading to an enhanced bronchodilation effect that would account for the improved outcome. In any case, patients receiving different combinations of therapy may not be homogeneous with respect to severity of asthma and other clinical characteristics, thus hampering comparison.

The main strengths of the present study are that it is a real-life investigation in a large number of patients managed according to the recommendations of clinical practice guidelines. It also evaluates efficacy and the conditions that facilitate efficacy.

Our study is subject to a series of limitations. It is a retrospective cohort study in which we analyzed a group of asthma patients without classifying them into endotypes, although it does try to evaluate the recommendations put forward in guidelines according to severity, irrespective of the patient's endotype. In addition, asthma was managed following clinical practice, and adherence was not recorded on the case report form, although it was always valued before the stepup (asked by the specialists at visits and/or using the Test of Adherence to Inhalers questionnaire) [14].

In summary, our study identified clinical tools that could be used to predict the outcome of step-up therapy. Previous studies only compared the enhanced performance of stepup therapy based on the ACT score in patients diagnosed with mild asthma [8]. Our approach facilitates the use of standard tools, which are generally easy to apply in clinical practice and improve the care of patients with uncontrolled severe/moderate asthma. In addition, evaluation of the variables used in the daily clinical care of these patients entails no increases in time or costs.

\section{Conclusions}

In daily practice, step-up therapy is based essentially on clinical criteria. The factors that determine whether or not this therapeutic strategy manages to control asthma are time since onset of clinical impairment, previous grade of severity, number of comorbidities, previous exacerbations, and frequency of symptoms.

\section{Acknowledgments}

We are grateful to Elena Casas, Dynamic, Madrid, Spain for the statistical analysis. The authors are also grateful to the participating investigators for their cooperation (List of Participating Investigators, Online Supplementary material).

\section{Funding}

This study was funded by Mundipharma Pharmaceuticals, Madrid, Spain.

\section{Conflicts of Interest}

Toni Fernández-Sánchez is an employee of Mundipharma Pharmaceuticals.

Eva Martinez Moragon:

- Grant/Research Support: AstraZeneca, GSK.

- Speaker's bureau: Novartis, TEVA, Chiesi, Sanofi, GSK, AstraZeneca, BIAL, and ALK

- Consultant: Novartis, TEVA, Sanofi, BoehringerIngelheim, Chiesi, AstraZeneca, GSK. 
Julio Delgado:

- Grant/Research Support: AstraZeneca and Orion.

- Speaker's bureau: AstraZeneca, Bial, Chiesi, GlaxoSmithKline, Novartis, and Sanofi

- Consultant: Bial, Novartis, and Sanofi.

\section{References}

1. Global Initiative for Asthma (GINA). Available from: http:// www.ginasthma.org/documents/1/Pocket-Guide-for-AsthmaManagement-and-Prevention.

2. Guía Española Para el Manejo del Asma (GEMA. Available from: www.gemasma.com)

3. Demoly P, Annunziata K, Gubba E, Adamek L. Repeated crosssectional survey of patient-reported asthma control in Europe in the past 5 years. Eur Respir Rev. 2012; 21:66-74.

4. Chipps BE, Corren J, Israel E, Katial R, Lang DM, Panettieri RA, et al. Practical recommendations for a sustained step-up in asthma therapy for poorly controlled asthma. Ann Allergy Asthma Immunol. 2017;118:133-42.

5. Lemanske RF, Mauger DT, Sorkness CA, Jackson DJ, Boehmer SJ, Martinez FD, et al. Step-up Therapy for Children with Uncontrolled Asthma While Receiving Inhaled Corticosteroids. N Engl J Med. 2010;362:975-85.

6. Murray CS, Thomas M, Richardson K, Price DB, Turner SW. Comparative Effectiveness of Step-up Therapies in Children with Asthma Prescribed Inhaled Corticosteroids: A Historical Cohort Study. J Allergy Clin Immunol Pract. 2017;5:1082-90.

7. Reddel HK, Taylor DR, Bateman ED, Boulet LP, Boushey HA, Busse WW, et al. Task Force on Asthma Control and Exacerbations. An Official American Thoracic Society/ European Respiratory Society Statement: Asthma Control and Exacerbations. Am J Respir Crit Care. 2009;180:59-99.

8. Lemanske RF, Mauger DT, Sorkness CA, Jackson DJ, Boehmer SJ, Martinez FD, et al Step-up Therapy for Children with Uncontrolled Asthma While Receiving Inhaled Corticosteroids. N Engl J Med. 2010; 362:975-85.
9. Quirce S, Plaza V, Picado C, Vennera M, J Casafont J. Prevalence of Uncontrolled Severe Persistent Asthma in Pneumology and Allergy Hospital Units in Spain J Investig Allergol Clin Immunol. 2011;21:466-71.

10. Holt S, Patel M, Mongomery B, Weatherall M, Beasley R. Cohort study of a simple 'Step-Up' regimen with the Asthma Control Test. Respirology. 2015;20;504-6.

11. Hurst JR, Dilleen M, Morris K, Hills S, Emir B, Jones R. Factors influencing treatment escalation from long-acting muscarinic antagonist monotherapy to triple therapy in patients with COPD: a retrospective THIN-database analysis. Int J Chron Obstruct Pulmon Dis. 2018;13:781-92.

12. Urrutia I, Delgado J, Domínguez-Ortega J, Mascarós E, Pérez $M$, Resler $G$, et al. Clinical factors associated with the overuse of asthma rescue medication. J Investig Allergol Clin Immunol. 2020; 30 (in press) doi: 10.18176/jiaci.0387

13. Harrison TW, Tattersfield AE. Plasma concentrations of fluticasone propionate and budesonide following inhalation from dry powder inhalers by healthy and asthmatic subjects. Thorax. 2003;58:258-60.

14. Plaza V, Fernández-Rodríguez C, Melero C, Cosio BG, Entrenas LM, López-Viña $A$, et al. Validation of the 'Test of the Adherence to Inhalers' (TAI) for asthma and COPD patients. J Aerosol Med Pulm Drug Deliv. 2016;29:142-52.

- Manuscript received June 11, 2019; accepted for publication December 10, 2019.

\section{- Julio Delgado Romero}

Allergology Clinical Management Unit

Hospital Virgen Macarena

Sevilla, Spain

E-mail: juliodelgadoromero@gmail.com 